\title{
Screen printed thick film based pMUT arrays
}

Hedegaard, Tobias; Pedersen, T; Thomsen, Erik Vilain; Lou-Møller, Rasmus; Hansen, K; Zawada, T

Published in:

IEEE Ultrasonics Symposium, 2008. IUS 2008.

Link to article, DOI:

10.1109/ULTSYM.2008.0526

Publication date:

2008

Document Version

Publisher's PDF, also known as Version of record

Link back to DTU Orbit

Citation (APA):

Hedegaard, T., Pedersen, T., Thomsen, E. V., Lou-Møller, R., Hansen, K., \& Zawada, T. (2008). Screen printed thick film based pMUT arrays. In IEEE Ultrasonics Symposium, 2008. IUS 2008. IEEE.

https://doi.org/10.1109/ULTSYM.2008.0526

\section{General rights}

Copyright and moral rights for the publications made accessible in the public portal are retained by the authors and/or other copyright owners and it is a condition of accessing publications that users recognise and abide by the legal requirements associated with these rights.

- Users may download and print one copy of any publication from the public portal for the purpose of private study or research.

- You may not further distribute the material or use it for any profit-making activity or commercial gain

- You may freely distribute the URL identifying the publication in the public portal 


\title{
Screen Printed Thick Film Based pMUT Arrays
}

\author{
T. Hedegaard, T. Pedersen, E. V. Thomsen \\ DTU Nanotech - Department of Micro and Nanotechnology \\ Technical University of Denmark \\ Lyngby, Denmark \\ Tobias.Hedegaard@nanotech.dtu.dk
}

\author{
R. Lou-Moeller \\ InSensor $\mathrm{A} / \mathrm{S}$ \\ Kvistgaard, Denmark
}

\author{
K. Hansen, T. Zawada \\ Ferroperm Piezoceramics A/S \\ Kvistgaard, Denmark
}

\begin{abstract}
This article reports on the fabrication and characterization of $\lambda$ pitched piezoelectric Micromachined Ultrasound Transducer (pMUT) arrays fabricated using a unique process combining conventional silicon technology and low cost screen printing of thick film PZT. The pMUTs are designed as 8 element membrane based devices dimensioned to operate in bending mode in the 1$10 \mathrm{MHz}$ regime. The devices are characterized using impedance measurements as well as acoustic pulse echo measurements. The characterization showed resonance frequencies for the bending mode around 6-8 MHz.
\end{abstract}

Keywords: pMUT; screen printed thick film PZT; arrayed elements; pulse echo

\section{INTRODUCTION}

In order to improve medical ultra sound imaging the requirements to the dimensions of the ultra sound transducers becomes more and more difficult to meet with conventional bulk PZT based devices [1]. Conventional pMUTs makes use of the $\mathrm{d}_{33}$ mode of the PZT also referred to as thickness mode. This article reports on fabrication of membrane based devices as shown in Fig. 1. This type of pMUTs uses the $d_{31}$ mode of the PZT to induce vibrations in the membrane and thus get a higher output of the device. This is referred to as the bending mode of the device. Silicon based pMUT devices offers the advantage of well founded process techniques which combined with either thick or thin film PZT can be used to fabricate miniaturized ultrasound transducers. Thin film PZT has the advantage of easy patterning compared to thick film PZT, but lacks in performance. Screen printing of thick film PZT is a technique that offers great advantages. The technique enables easy patterning of the PZT and very precise control of the thickness of the PZT layer. Furthermore this process has through process development been made compatible with conventional silicon technology used to fabricate the membrane structure for the pMUT devices [2]. The design of the pMUT devices is an array of 8 rectangular silicon membranes made to resonate at their resonance frequency by a PZT layer on top of the silicon membranes. A cross sectional

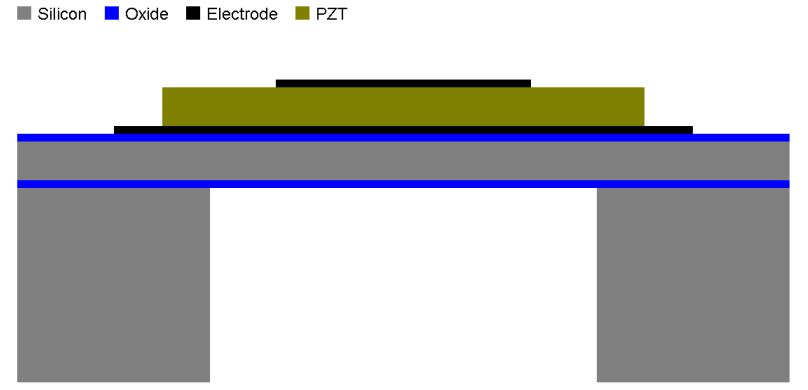

Figure 1 Cross sectional view of single pMUT element. Silicon is used as supporting structure and as membrane. On top of the membrane and the bottom electrode the PZT is screen printed and finally a top electrode is deposited.

view of the device is shown in Fig. 1. Both the supporting structures and the membrane are made of silicon and the PZT is situated on top of the membrane between the two electrodes. The dimensions of the membrane are optimized using a finite element model. The devices are characterized using impedance measurements to verify the resonance frequency and acoustic pulse/echo measurements to investigate the acoustic properties of the devices.

\section{DESIGN}

The simple design of the pMUT device offers great opportunities to vary the resonance frequency of the ultra sound transducer without changing the fabrication procedure. Thus the transducers can be used in a wide range of applications, by changing the width and the thickness of the membrane. The device is designed to operate in bending mode, but thickness mode resonance will also occur. The fabrication process and the design enables $\lambda$-pitching of the individual elements which is crucial in order to make high quality ultra sound images. The design of the device makes it possible to use the individual elements as both transmitters and receivers. As seen on the illustration of the device in Fig. 2 the top electrodes (magenta dots) are routed via thin wires to bonding pads (blue dots) located at places on the PZT (black dot) without bottom 


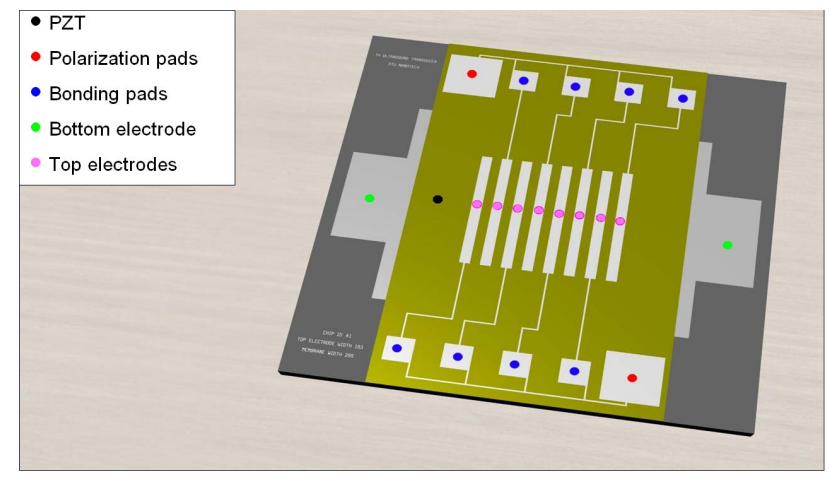

Figure 2 Illustration of final pMUT device. The size of the device is $8 \mathrm{x} 8$ $\mathrm{mm}$. To ease the polarization the top electrodes are connected to two polarization pads via thin wires. These wires are subsequently diced in order to be able to operate the top electrodes individually.

electrode (green dots) underneath. This is done to prevent parasitic capacitances. The top electrodes are all connected to the polarization pads (red dots) for easy polarization. The connections between these are subsequently diced so the top electrodes are electrically separated.

\section{Finete ELEMENT MODEL (FEM)}

Prior to fabricating the pMUT devices the design was modelled in the FEM tool COMSOL. The PZT has a Youngs modulus of $62.5 \mathrm{GPa}$. This numbers are included in the model. A simple 2D model was used assuming that the central part of the rectangular membranes behaves as a double clamped beam. The purpose of the model was to give a first estimate of which dimensions would lead to resonance frequencies in the wanted $1-10 \mathrm{MHz}$ regime. The length of the membranes was fixed at $2.5 \mathrm{~mm}$ and the thickness at $20 \mu \mathrm{m}$. The width was varied from $150 \mu \mathrm{m}$ to $300 \mu \mathrm{m}$. The thickness of the different layers is listed in Table 1. The resonance frequency for the device was modelled neglecting the internal stress in the PZT layer and in Fig. 3 a plot of the resonance frequency as function of the width of the membranes is shown. The data are proportional to one divided by the squared width as expected from beam theory.

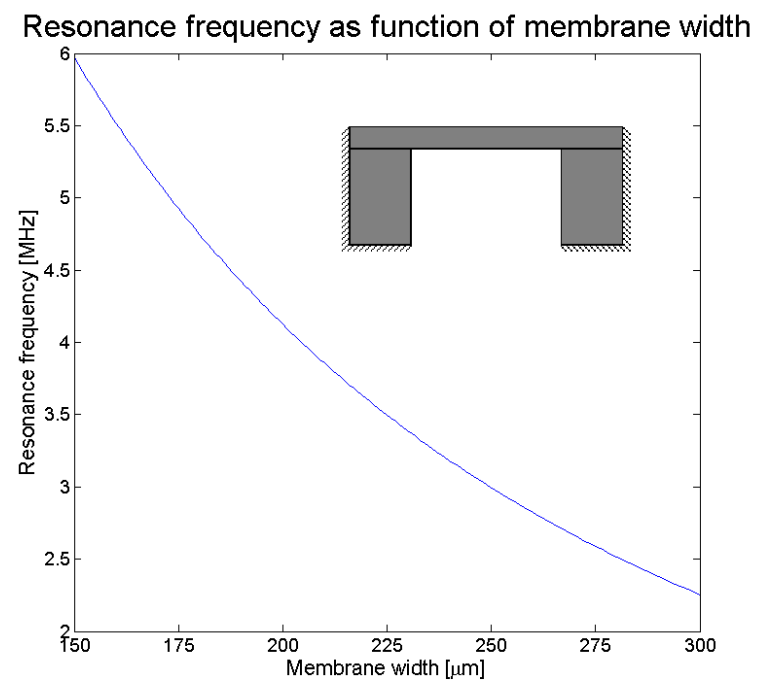

Figure 3 Modeled resonance frequencies as function of membrane width. The inset shows a schematic drawing of the modeled structure. The structure is clamped on the bottom and on the outermost sidewalls.

\section{FABRICATION}

The fabrication is a four step process, three steps carried out in a cleanroom for conventional silicon processing and one step carried out at a separate cleanroom facility dealing with the screen printing of thick film PZT. The process is robust, simple and low cost as many devices can be fabricated from one single wafer. The fabrication starts out with a Silicon On Insulator (SOI) wafer with a silicon dioxide layer thermally grown on top of the device layer. Fig. 5 shows a schematic drawing of the process. In Fig. 5a) cavities are etched from the backside of the wafer to form the $20 \mu \mathrm{m}$ thick membranes using an Advanced Silicon Etch (ASE) and a photo sensitive polymer (AZ4562) as masking material. Another possibility of etching the cavities was to use $\mathrm{KOH}-$ an anisotropic wet etch as reported in [1]. This etching technique however results in sidewalls with an angle of 54.7 degrees and is thus not suitable for making pMUT devices with arrays of membranes as the spacing between the individual membranes would be too large. Using the ASE nearly vertical sidewalls can be obtained as seen in Fig. 4. At the membranes silicon spikes are seen. These are artefacts of the ASE. By optimizing the ASE process recipe the problem with these artefacts has now been solved. The nearly vertical sidewalls make it possible to obtain $\lambda$-pitching of the elements which is preferable in medical ultra sound imaging. The buried silicon dioxide layer is used as an etch stop as the ASE has a very high selectivity between silicon and silicon dioxide (80:1). In Fig. 5b) the bottom electrode is deposited using electron beam evaporation of titanium and platinum. The bottom electrode is patterned using a photo sensitive polymer (AZ4562) to perform a lift off process. The combination of titanium and platinum is chosen as this on top of the silicon dioxide layer serves as a conductive diffusion barrier between silicon and the PZT [3]. Fig. 5c)-e) shows the thick film PZT screen printing. The screen printing technique facilitates deposition and patterning of the PZT in one process as well as control of the thickness with high precision. In Fig. 1 the final device is shown with the top electrode deposited on top of the PZT. The top electrode is, like the bottom electrode, deposited using electron beam evaporation and a photo sensitive polymer (AZ4562) to pattern the metal. Aluminium is chosen as this metal has good adherence to the PZT. A cross sectional image from a Scanning Electron Microscope (SEM) of a single element is shown in Fig. 6. After depositing the top electrode the pMUT devices are separated using a diamond blade rotating saw and the individual devices are polarized. In Table I the dimensions of the different layers of the device are specified.

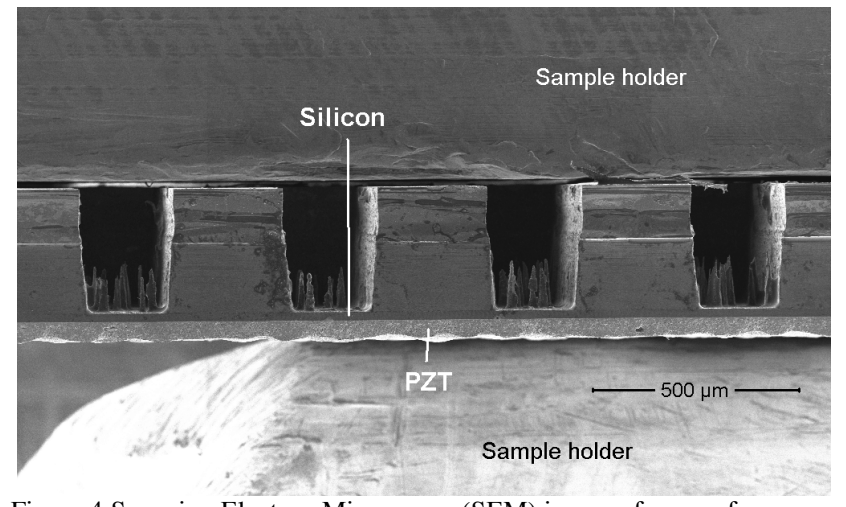

Figure 4 Scanning Electron Microscopy (SEM) image of array of membranes. The width at the bottom of the cavities is $192 \mu \mathrm{m}$ and the spacing is around $500 \mu \mathrm{m}$. The sidewalls are seen to be nearly vertical. 

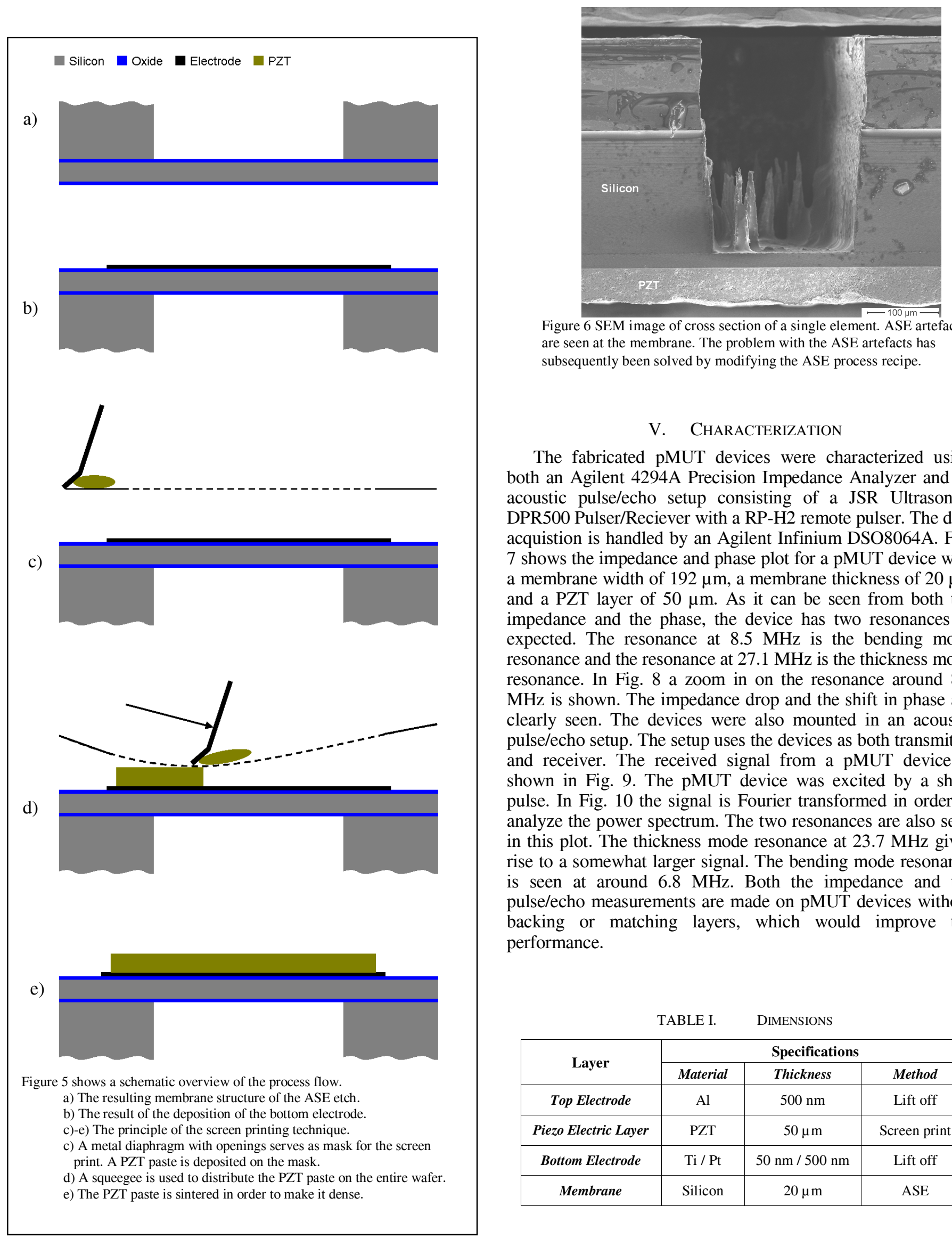

Figure 6 SEM image of cross section of a single element. ASE artefacts are seen at the membrane. The problem with the ASE artefacts has subsequently been solved by modifying the ASE process recipe.

\section{CHARACTERIZATION}

The fabricated pMUT devices were characterized using both an Agilent 4294A Precision Impedance Analyzer and an acoustic pulse/echo setup consisting of a JSR Ultrasonics DPR500 Pulser/Reciever with a RP-H2 remote pulser. The data acquistion is handled by an Agilent Infinium DSO8064A. Fig. 7 shows the impedance and phase plot for a pMUT device with a membrane width of $192 \mu \mathrm{m}$, a membrane thickness of $20 \mu \mathrm{m}$ and a PZT layer of $50 \mu \mathrm{m}$. As it can be seen from both the impedance and the phase, the device has two resonances as expected. The resonance at $8.5 \mathrm{MHz}$ is the bending mode resonance and the resonance at $27.1 \mathrm{MHz}$ is the thickness mode resonance. In Fig. 8 a zoom in on the resonance around 8.5 $\mathrm{MHz}$ is shown. The impedance drop and the shift in phase are clearly seen. The devices were also mounted in an acoustic pulse/echo setup. The setup uses the devices as both transmitter and receiver. The received signal from a pMUT device is shown in Fig. 9. The pMUT device was excited by a short pulse. In Fig. 10 the signal is Fourier transformed in order to analyze the power spectrum. The two resonances are also seen in this plot. The thickness mode resonance at $23.7 \mathrm{MHz}$ gives rise to a somewhat larger signal. The bending mode resonance is seen at around $6.8 \mathrm{MHz}$. Both the impedance and the pulse/echo measurements are made on pMUT devices without backing or matching layers, which would improve the performance.

TABLE I. DIMENSIONS

\begin{tabular}{|c|c|c|c|}
\hline \multirow{2}{*}{ Layer } & \multicolumn{3}{|c|}{ Specifications } \\
\cline { 2 - 4 } Top Electrode & Material & Thickness & Method \\
\hline Piezo Electric Layer & $\mathrm{Al}$ & $500 \mathrm{~nm}$ & Lift off \\
\hline Bottom Electrode & $\mathrm{Ti} / \mathrm{Pt}$ & $50 \mu \mathrm{m}$ & Screen print \\
\hline Membrane & Silicon & $20 \mu \mathrm{m}$ & ASE \\
\hline
\end{tabular}




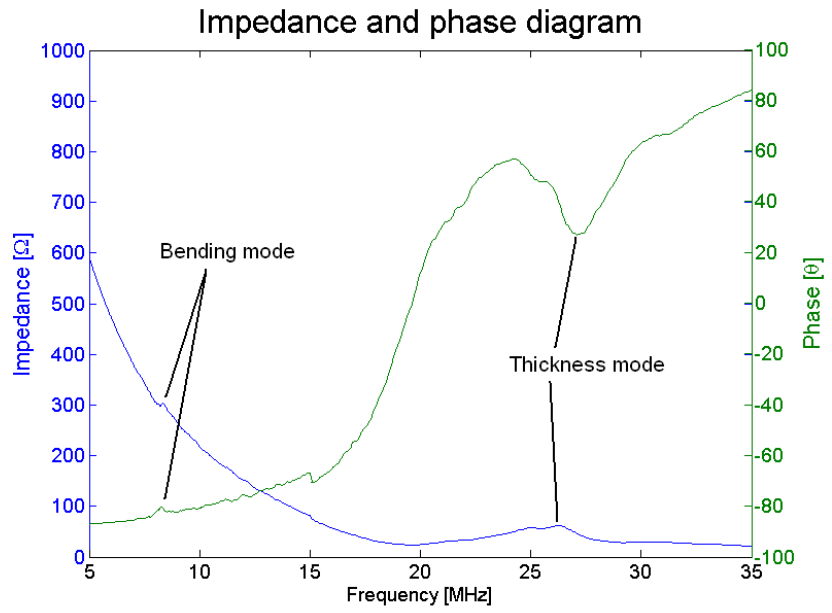

Figure 7 Impedance and phase plot of measurements performed on a pMUT device. The two expected resonance frequencies are indicated bending mode resonance at $8.5 \mathrm{MHz}$ and thickness mode resonance at 27.1 $\mathrm{MHz}$. The feature at $15 \mathrm{MHz}$ is a result of the measurement setup.

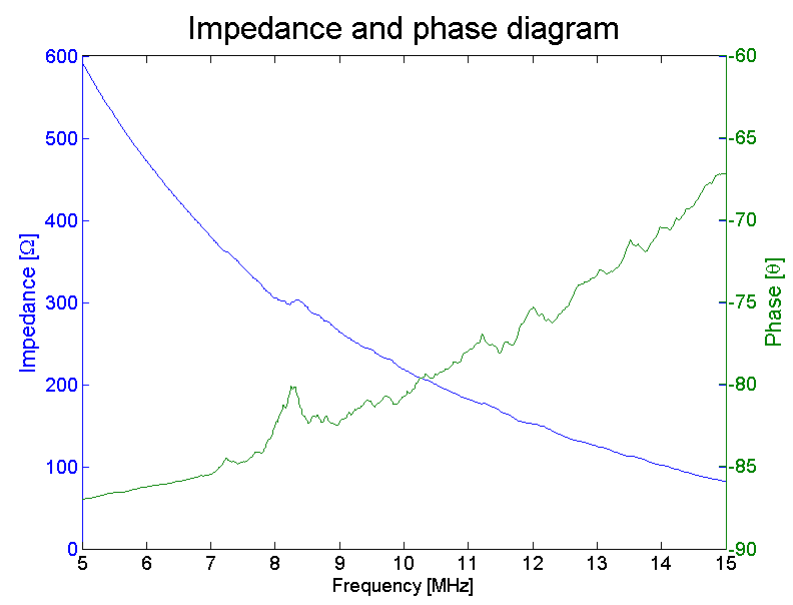

Figure 8 Zoom in on the resonance at around $8.5 \mathrm{MHz}$. A change in the phase of around 5 degrees is seen.

\section{Pulse-echo signal}

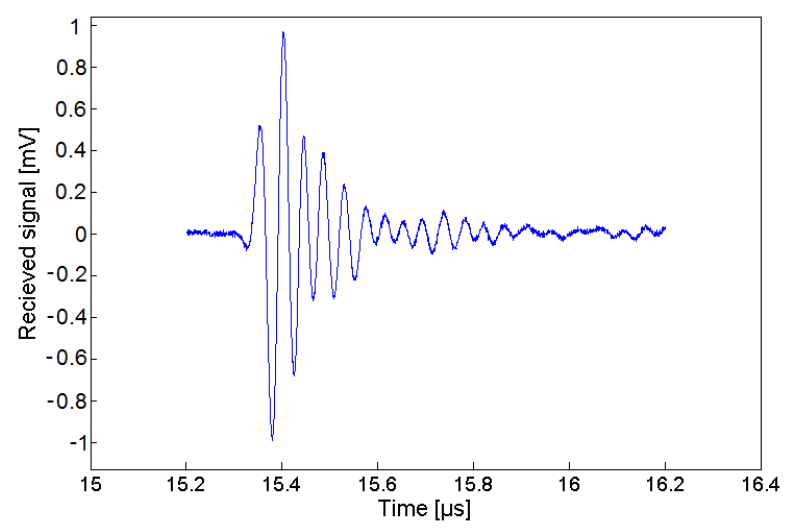

Figure 9 The received signal from the pMUT device. The device is measured in the pulse/echo setup without backing layer. A backing layer would reduce the ringing in the device. Ideally only one sine wave should be seen.

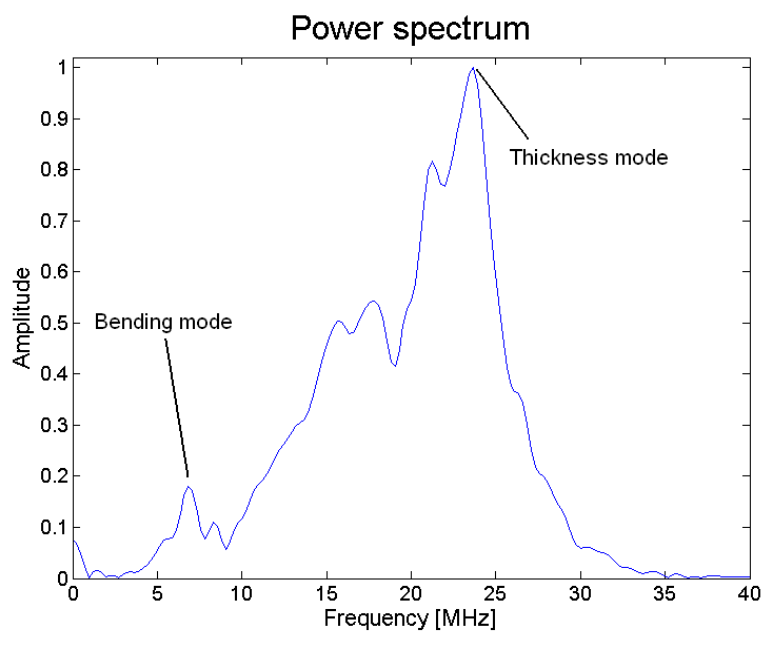

Figure 10 Power spectrum of the received signal. The bending mode and thickness mode resonances are seen around $6.8 \mathrm{MHz}$ and 23.7 $\mathrm{MHz}$ respectively.

\section{CONCLUSION}

A fabrication process combining conventional silicon processing technologies and screen printing of thick film PZT was reported. The fabrication process enables the fabrication of arrays of $\lambda$-pitched membrane type pMUT elements with uniform membrane thicknesses. The pMUT devices were characterized using impedance analysis and acoustic pulse/echo measurements. The bending mode resonance frequency of the devices was measured to be between 6.8 and $8.5 \mathrm{MHz}$ using both impedance analysis and pulse/echo measurements. The thickness mode resonance was measured to be between 23.7 and 27.1 MHz. Table II summarizes the results of the measurements. In both cases bending mode resonance is higher than the modelled value. This is believed to be due to internal stress in the PZT layer.

TABLE II. RESULTS

\begin{tabular}{|c|c|c|c|}
\hline & $\begin{array}{c}\text { Impedance } \\
\text { measurements }\end{array}$ & $\begin{array}{c}\text { Pulse/echo } \\
\text { measurements }\end{array}$ & $\begin{array}{c}\text { FEM } \\
\text { Model }\end{array}$ \\
\hline $\begin{array}{c}\text { Bending mode } \\
\text { resonance }\end{array}$ & $8.5 \mathrm{MHz}$ & $6.8 \mathrm{MHz}$ & $4.5 \mathrm{MHz}$ \\
\hline $\begin{array}{c}\text { Thickness mode } \\
\text { resonance }\end{array}$ & $27.1 \mathrm{MHz}$ & $23.7 \mathrm{MHz}$ & - \\
\hline
\end{tabular}

\section{REFERENCES}

[1] Z. Wang, J. Miao, and W. Zhu, "Micromachined ultrasonic transducers and arrays based on piezoelectric thick film", Appl. Phys. A 91, 107-117 (2008)

[2] R. Lou-Moeller, C.C. Hindrichsen, L.H. Thamdrup, T. Bove, E. Ringgaard, A.F. Pedersen, Erik V. Thomsen, "Screen-Printed Piezoceramic Thick Films for Miniaturised Devices", Journal of Electroceramics, Vol. 19, Issue 4, pp. 333-338 (2007)

[3] C. C. Hindrichsen, T. Pedersen, E. V. Thomsen, K. Hansen, R. LouMøller, "Investigation of Top/Bottom Electrode and Diffusion Barrier Layer for PZT Thick Film MEMS Sensors", GFER: Ferroelectrics, in press 